\title{
Treating hyperglycemia improves skeletal muscle protein metabolism in cancer patients after major surgery
}

\author{
Gianni Biolo, MD, PhD; Marcello De Cicco, MD; Stefania Lorenzon, MD; Viviana Dal Mas, MD; Dario Fantin, \\ MD; Rita Paroni, MD; Rocco Barazzoni, MD; Michela Zanetti, MD; Gaetano lapichino, MD; Gianfranco \\ Guarnieri, MD
}

\begin{abstract}
Objective: Cancer and surgical stress interact to aggravate insulin resistance, protein catabolism, and glutamine depletion in skeletal muscle. We compared the effects of insulin-mediated euglycemia and moderate hyperglycemia on kinetics of protein and selected amino acids in skeletal muscle of female cancer patients after major surgery.

Design: In each patient, a 24-hr period of insulin-mediated tight euglycemia (mean blood glucose, $5.8 \pm 0.4 \mathrm{mmol} / \mathrm{L}$ ) preceded or followed a 24-hr control period of moderate hyperglycemia (mean blood glucose, $9.6 \pm 0.6 \mathrm{mmol} / \mathrm{L}$ ) on the first and second day after surgery, in randomized order, according to a crossover experimental design.

Setting: Intensive care unit, cancer hospital.
\end{abstract}

Patients: Cancer patients after abdominal radical surgery combined with intraoperative radiation therapy.

Interventions: Intensive (57 $\pm \mathbf{1 1}$ units/24 hrs) and conventional (25 \pm 5 units/24 hrs) insulin treatment during total parenteral nutrition.

Measurements and Main Results: Muscle metabolism was assessed at the end of each 24-hr period of euglycemia and of hyperglycemia by leg arteriovenous catheterization with stable isotopic tracers. We found that euglycemia as compared with hyperglycemia was associated with higher $(p<.05)$ fractional glucose uptake $(16 \% \pm 4 \%$ vs. $9 \% \pm 3 \%)$; higher $(p<.05)$ muscle protein synthesis and neutral net protein balance $(-3 \pm$ 3 vs. $-11 \pm 3 \mathrm{nmol}$ phenylalanine $\cdot 100 \mathrm{~mL}^{-1} \cdot \mathrm{min}^{-1}$, respectively); lower $(-52 \% \pm 12 \%, p<.01)$ muscle nonprotein leucine disposal (an index of leucine oxidation) and higher $(p<.05)$ plasma leucine concentrations; and higher $(3.6 \pm 1.7$ times, $p<.01)$ net de novo muscle glutamine synthesis and plasma glutamine concentrations $(p<.05)$. Euglycemia was associated with higher $(23 \% \pm 7 \%, p<.05)$ plasma concentrations of arginine but did not affect either arginine release from muscle or plasma concentration and muscle flux of asymmetrical dimethylarginine. Rate of muscle proteolysis correlated $(p<.05)$ with muscle release of asymmetrical dimethylarginine.

Conclusions: Treating hyperglycemia improves skeletal muscle protein and amino acid metabolism in cancer patients after major surgery. (Crit Care Med 2008; 36:1768-1775)

KEY WORDS: insulin; cancer; surgery; skeletal muscle; glycemic control; glutamine; arginine

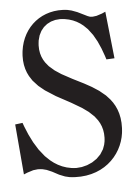

keletal muscle plays a pivotal role in metabolic adaptation to severe stress. Muscle resistance to insulin's ability to promote glucose uptake and metabolism di-

*See also p. 1965.

From the Division of Internal Medicine, Department of Clinical, Morphological and Technological Sciences, University of Trieste, Trieste, Italy (GB, SL, VDM, RB, MZ, GG); Intensive Care Unit, National Cancer Institute, Aviano, Italy (MDC, DF); Department of Medicine, Surgery, and Dental Science (RP), and the Intensive Care Unit (Gl), University of Milan, Milan, Italy.

The authors have not disclosed any potential conflicts of interest.

Supported, in part, by grants from "Ministero Università Ricerca Scientifica e Tecnologica" PRIN 2003 and from Novartis Medical Nutrition.

For information regarding this article, E-mail: biolo@units.it

Copyright $\odot 2008$ by the Society of Critical Care Medicine and Lippincott Williams \& Wilkins

DOI: 10.1097/CCM.0b013e318174de32 rectly contributes to increasing blood glucose in patients affected by critical illness or recovering from major surgery (1). Hyperglycemia has direct negative effects on endothelial and immune functions (2). Activation of muscle proteolysis with relative inhibition of protein synthesis leads to muscle wasting and efflux of free amino acids (3). Glutamine has the fastest releasing rate because it is largely synthesized de novo and stored in muscle cytoplasm. In critical illness and after major surgery, the muscle glutamine pool is rapidly depleted to provide free glutamine both to the liver and rapidly dividing cells of gut mucosa and the immune system (4). Such increased utilization is not matched by sufficient muscle production (5-7). In addition to amino acids, asymmetrical (ADMA) and symmetrical (SDMA) dimethylarginines, produced by methylation of arginine resi- dues in proteins, are also released from skeletal muscle as obligatory products of protein turnover (8). ADMA is an endogenous inhibitor of nitric oxide synthase that may cause endothelial dysfunction (8). In the clinical setting, hyperglycemia, glutamine depletion, and increased ADMA concentrations were associated with poor outcome in critically ill patients $(4,9,10)$. Insulin-mediated strict glucose control and glutamine supplementation decreased morbidity and mortality in selected patients $(4,9)$.

The present study was designed to explore potential interactions between pathways of glucose and amino acid metabolism in skeletal muscle of intensive care patients. In skeletal muscle, glucose serves as a precursor for the carbon skeleton of glutamine (11). Under physiologic conditions, glutamine release from skeletal muscle increases during euglycemic 
hyperinsulinemia $(12,13)$ because of increased conversion of glucose to glutamine. A recent study has determined the effect of hyperglycemia on carbon transfer rate from glucose to glutamine during intravenous dextrose infusion in healthy volunteers and insulin-deprived type 1 diabetic subjects (11). Hyperglycemia in healthy subjects stimulated carbon flux from glucose to glutamine, whereas the rise in carbon transfer from glucose to glutamine was not observed in diabetic subjects. These results suggest that carbon transfer from glucose to glutamine may depend on adequate insulin availability and action. Hyperglycemia can also increase ADMA levels by inhibiting methylarginine intracellular enzymatic degradation by the enzyme dimethylarginine dimethylaminohydrolase (8). Finally, insulin and glucose availability have deep influence on the synthesis and degradation pathways of muscle protein and on oxidation of individual amino acids, especially branched chain $(14,15)$.

We have selected a population of slightly overweight patients with cancer who underwent abdominal radical surgery combined with intraoperative radiation therapy $(16,17)$ to maximize muscle metabolic alterations $(4,18-20)$, such as insulin resistance, acceleration of proteolysis, inhibition of protein synthesis, and glutamine depletion. A 2-day crossover experimental design was used to compare the effects of moderate hyperglycemia and euglycemia, resulting from 24 hrs of traditional or intensive insulin treatment, on the rates of skeletal muscle protein synthesis and degradation, leucine oxidation, glutamine de novo synthesis, and dimethylarginine production, as determined by the leg arteriovenous catheterization and stable isotopic tracers $(21,22)$.

\section{METHODS}

Patients. We have studied eight adult female patients (age, $54 \pm 4$ yrs; body mass index, $\left.26 \pm 2 \mathrm{~kg} / \mathrm{m}^{2}\right)$ with colorectal $(\mathrm{n}=3)$, cervical $(n=1)$, endometrial $(n=1)$, ovarian $(\mathrm{n}=2)$, and kidney $(\mathrm{n}=1)$ cancer and no major organ-system diseases, after the complete surgical removal of the tumor in combination with intraoperative radiation therapy $(16,17)$. Informed consent was obtained from patients before surgery. The experimental protocol was approved by the ethical committee of the Centro di Riferimento Oncologico (CRO), Istituto Nazionale Tumori, IRCCS, Aviano, Italy. After surgery, patients were admitted to the intensive care unit of the Centro di Riferimento Oncologico of Aviano, Italy. A continuous intravenous infusion of glucose $\left(20 \%\right.$ solution at $\left.20 \mathrm{~mL} \cdot \mathrm{kg}^{-1} \cdot \mathrm{day}^{-1}\right)$, lipids (Intralipid 10\% [Fresenius Kabi AB] at 8 $\mathrm{mL} \cdot \mathrm{kg}^{-1} \cdot \mathrm{day}^{-1}$ ), and mixed amino acids (Freamine III 8.5\% [B. Braun Medical] at 14.4 $\mathrm{mL} \cdot \mathrm{kg}^{-1} \cdot \mathrm{day}^{-1}$ ) was initiated and continued for the following $48 \mathrm{hrs}$. Total energy administration was $28 \mathrm{kcal} \cdot \mathrm{kg}^{-1} \cdot \mathrm{day}^{-1}$.

Experimental Design. Each patient was studied twice. Two leg muscle metabolic studies (which included determination of whole body and muscle protein and amino acid metabolism) were performed at the end of the 24-hr periods of conventional or tight glycemic control. To account for time-related changes of muscle metabolism after surgery and for potential interference between two close stable-isotope infusions, the conventional glycemic control period either preceded (protocol 1) or followed (protocol 2) the tight glycemic control period. Patients were randomly assigned to protocol $1(\mathrm{n}=4)$ or to protocol $2(n=4)$. In the patients assigned to protocol 1, a conventional insulin treatment was started after surgery at about 11 am and continued for 24 hrs (i.e., a continuous infusion of regular insulin was started only if the blood glucose level exceeded $9.4 \mathrm{mmol} / \mathrm{L}$, and the infusion was adjusted to maintain the glucose level at a value between 8.3 and 11.1 $\mathrm{mmol} / \mathrm{L}$ ). In the patients assigned to protocol 2 , an intensive insulin treatment was started after surgery at about 11 am and continued for 24 hrs (i.e., an insulin infusion was started if the blood glucose level exceeded $6.1 \mathrm{mmol} / \mathrm{L}$, and the infusion was adjusted to maintain normoglycemia [ 4.4 to $6.9 \mathrm{mmol} / \mathrm{L}]$ ) (9). The next day, a leg muscle metabolic study was performed in all patients from 8 to $11 \mathrm{am}$. Thereafter, in the four patients who previously received conventional insulin treatment, an intensive insulin treatment was started and was continued for $24 \mathrm{hrs}$. In the other four patients who previously received intensive insulin treatment, a 24-hr conventional insulin treatment was commenced. The second metabolic study was performed from 8 to 11 am during the last 3 hrs of either conventional or intensive insulin treatment. During the two study days, blood glucose concentrations were determined approximately every 2 hrs.

Leg Metabolic Study. On the morning of the first day after surgery, the first leg muscle metabolic study was performed from 8 am to $11 \mathrm{am}$. Indwelling catheters placed for clinical purposes in a femoral and internal jugular vein and in a radial artery were used for isotope infusion and blood sampling. At 8 am, femoral venous blood samples were obtained to measure background phenylalanine enrichment. Then, primed, continuous infusions of L-[ring- ${ }^{2} \mathrm{H}_{5}$ ]phenylalanine (Cambridge Isotope Laboratories) were started and maintained constant for $3 \mathrm{hrs}$ (prime dose, $1 \mu \mathrm{mol} /$ $\mathrm{kg}$; infusion rate, $0.02 \mu \mathrm{mol} \cdot \mathrm{kg}^{-1} \cdot \mathrm{min}^{-1}$ ). After 160 mins, three blood samples were taken every 10 mins from the radial artery and the femoral vein to determine plasma glucose and amino acid concentrations and phenylal- anine enrichments. Leg blood flow was measured by plethysmography after every blood sample (22). Leg plasma flow was calculated from the hematocrit. Infusion of labeled phenylalanine was stopped at time 180 mins. On the morning of the second day after surgery, the second leg muscle metabolic study was performed from 8 am to $11 \mathrm{am}$, as described.

Analysis. Concentrations of selected amino acids (phenylalanine, leucine, and glutamine) and isotopic enrichment of L-[ring${ }^{2} \mathrm{H}_{5}$ ]phenylalanine were measured in plasma samples taken from the radial artery and femoral vein, as previously described $(21,22)$. The stable isotopes L- $\left[1-{ }^{13} \mathrm{C}\right]$ phenylalanine, L-[1$\left.{ }^{13} \mathrm{C}\right]$ leucine, and $\mathrm{L}-\left[5^{15} \mathrm{~N}\right]$ glutamine were added to the tubes as internal standards (22). To determine the enrichment of the infused tracer and the internal standards of free phenylalanine, leucine, and glutamine in the plasma, the t-butyldimethylsilyl derivatives were prepared as described by Biolo et al (21). Tracer/tracee ratios were measured by gas chromatography-mass spectrometry analysis (Hewlett-Packard 5985) (21). Plasma concentrations of arginine, ADMA, and SDMA were determined by high-pressure liquid chromatography, as previously described (23). Insulin, C-peptide, and glucose concentrations were determined by standard methods.

Calculations. Calculations of glucose and amino acid kinetics used averaged values of plasma concentrations and enrichments obtained at the end of each leg metabolic study. Skeletal muscle is considered to largely account for glucose and amino acid metabolism in the whole leg (21). The leg muscle net balance for glucose and amino acids was calculated from the Fick principle:

$$
\text { Net balance }=\left(\mathrm{C}_{\mathrm{A}}-\mathrm{C}_{\mathrm{V}}\right) \cdot \mathrm{F}
$$

where $\mathrm{C}_{\mathrm{A}}$ and $\mathrm{C}_{\mathrm{V}}$ are plasma glucose or amino acid concentrations in radial artery and femoral vein, respectively, and $\mathrm{F}$ is leg plasma flow. Positive values indicate net uptake, whereas negative values indicate net release. In steadystate condition of amino acid concentrations, amino acid uptake or release across the leg reflects the balance between intracellular production and disposal for that particular amino acid. Thus, net phenylalanine release from leg muscle is a marker of net protein catabolism (i.e., the difference between protein synthesis and degradation) because this amino acid is not synthesized or oxidized in muscle tissue $(21,22,24)$. In contrast, skeletal muscle is the main site of oxidation of the branched-chain amino acids leucine, valine, and isoleucine and of glutamine synthesis from glutamate. We assumed that amino acids are released from protein catabolism in proportion to their relative content in muscle proteins (21). Thus, the net rates of release from protein catabolism of leucine and glutamine can be calculated from the net rate of phenylalanine release corrected for the molar ratios glutamine/ 
phenylalanine (i.e., 0.92) and leucine/ phenylalanine (i.e., 3.10) determined in mixed human muscle protein (21). The rate of net glutamine de novo synthesis (i.e., the differences between the rates of de novo synthesis and nonprotein utilization of the amino acid) and of nonprotein leucine disposal (i.e., and index of leucine oxidation) can be calculated by subtracting the component accounted for by protein catabolism from the total release or uptake of these amino acids (glutamine de novo synthesis was transformed into a positive number):

Glutamine de novo synthesis

$$
=-[\text { net glutamine balance }
$$

- (net phenylalanine balance $\times 0.92)]$

Nonprotein leucine disposal

$$
\begin{gathered}
=\text { [net leucine balance } \\
- \text { (net phenylalanine balance }
\end{gathered}
$$

whole body phenylalanine rate of appearance (Ra) from proteolysis and exogenous infusion was calculated by standard methodology (i.e., by dividing $\mathrm{L}$-[ring- ${ }^{2} \mathrm{H}_{5}$ ]phenylalanine infusion rate by arterial L-[ring- ${ }^{2} \mathrm{H}_{5}$ ]phenylalanine tracer/ tracee ratio). Phenylalanine Ra from whole body proteolysis was calculated by subtracting the infusion rate of exogenous unlabeled phenylalanine (i.e., $0.3 \mu \mathrm{mol} \cdot \mathrm{kg}^{-1} \cdot \mathrm{min}^{-1}$ ) from total whole body phenylalanine rate of appearance.

Muscle phenylalanine Ra from proteolysis was calculated as follows (21, 22, 24):

Phenylalanine Ra from proteolysis

$$
\begin{array}{r}
=\left[\left(\mathrm{C}_{\mathrm{A}(\mathrm{PHE})} \times \mathrm{E}_{\mathrm{A}(\mathrm{PHE})} \times \mathrm{BF}\right) / \mathrm{E}_{\mathrm{V}(\mathrm{PHE})}\right] \\
-\left(\mathrm{C}_{\mathrm{A}(\mathrm{PHE})} \times \mathrm{F}\right)
\end{array}
$$

$\mathrm{C}$ and $\mathrm{E}$ indicate values of arterial (A) or femoral venous $(\mathrm{V})$ phenylalanine (PHE) concentrations and enrichments, respectively.
Leg muscle phenylalanine rate of disappearance $(\mathrm{Rd})$ to muscle protein synthesis was calculated as follows $(21,22,24)$ :

Phenylalanine Rd to protein synthesis

$=$ Phenylalanine Ra from proteolysis

$$
+ \text { Net phenylalanine balance }
$$

Insulin sensitivity was determined according to the quantitative insulin-sensitivity check index (QUICKI) that is determined by a mathematical transformation of plasma glucose and insulin levels as follows (25):

$$
\text { QUICKI }=1 /[\log (\mathrm{I})+\log (\mathrm{G})]
$$

where I is plasma insulin concentration (microunits $/ \mathrm{mL}$ ) and $\mathrm{G}$ is plasma glucose concentration $(\mathrm{mg} / \mathrm{dL})$. QUICKI is a dimensionless index without units. During each study day, values of blood glucose concentrations, determined approximately every $2 \mathrm{hrs}$, were plotted on a graph. The area under the curve was calculated geometrically from 12 values of blood glucose concentrations as referenced (26). Units for area under the curve are blood glucose concentrations $\left(\mathrm{mmol} \cdot \mathrm{L}^{-1}\right) \times 24 \mathrm{hrs}$.

Data Presentation and Statistics. Each patient was studied twice. Two leg muscle metabolic studies (which included determination of whole body and muscle protein and amino acid metabolism) were performed at the end of 24-hr periods of conventional (control) or tight glycemic control (euglycemia). To account for time-related changes of muscle metabolism after surgery and for potential interference between two close stable-isotope infusions, patients were randomly assigned to protocol $1(n=4)$ or to protocol $2(n=4)$. In protocol 1, the euglycemic period preceded the hyperglycemic control period. In protocol 2 , the euglycemic period followed the hyperglycemic control period. Results obtained in the euglycemic and control periods in subjects assigned to protocols 1 and 2 were analyzed with repeated-measures analysis of variance with intervention (euglycemia/control) and time (day 1/day 2 after surgery) as the two factors. Post hoc analysis was performed, when appropriate, by Student's $t$-test with Bonferroni's adjustment. There were not significant time effects or significant intervention $\times$ time interaction for any clinical, biochemical, or kinetic data. Thus, results obtained during the euglycemic periods on day 1 or day 2 after surgery were pooled together and compared with the pooled results obtained during the hyperglycemic control periods on day 1 or day 2 after surgery. Results in the two different experimental conditions (control and euglycemia) were compared using the Wilcoxon's matched-pairs signedranks test. Values of substrate balance across leg muscle were tested against zero by the Wilcoxon's matched-pairs signed-ranks test to detect significant net release or uptake. Values of $p<.05$ were taken as significantly different. Data are presented in Tables $1-3$ as mean \pm SEM. Individual kinetic results and median values are shown in Figures 1-3.

\section{RESULTS}

Clinical Data and Glucose Kinetics. Table 1 shows selected clinical data during the two study days. Patients were hemodynamically stable, as shown by the values of systolic and diastolic arterial pressure, heart rate, leg plasma flow, and hematocrit determined during the two metabolic studies performed on days 1 and 2 after surgery, either in euglycemia or hyperglycemia (control period). Plasma creatinine and albumin concen-

\begin{tabular}{|c|c|c|c|c|c|c|c|}
\hline & \multicolumn{2}{|c|}{ Protocol 1} & \multicolumn{2}{|c|}{ Protocol 2} & \multicolumn{3}{|c|}{$p$} \\
\hline & $\begin{array}{c}\text { Day } 1 \\
\text { Euglycemia }\end{array}$ & $\begin{array}{c}\text { Day } 2 \\
\text { Control }\end{array}$ & $\begin{array}{c}\text { Day } 1 \\
\text { Control }\end{array}$ & $\begin{array}{c}\text { Day } 2 \\
\text { Euglycemia }\end{array}$ & $\begin{array}{l}\text { Time } \\
\text { Effect }\end{array}$ & $\begin{array}{l}\text { Intervention } \\
\text { Effect }\end{array}$ & Interaction \\
\hline SAP (mm Hg) & $133 \pm 11$ & $132 \pm 9$ & $136 \pm 5$ & $131 \pm 4$ & .91 & .42 & .19 \\
\hline DAP (mm Hg) & $74 \pm 7$ & $75 \pm 5$ & $75 \pm 3$ & $74 \pm 4$ & .99 & .80 & .96 \\
\hline Heart rate (beats/min) & $79 \pm 5$ & $80 \pm 3$ & $85 \pm 4$ & $86 \pm 3$ & .28 & .88 & .47 \\
\hline Plasma creatinine (mg/dL) & $0.92 \pm 0.05$ & $0.89 \pm 0.01$ & $0.81 \pm 0.06$ & $0.82 \pm 0.05$ & .21 & .45 & .56 \\
\hline Plasma albumin $(\mathrm{g} / \mathrm{L})$ & $3.2 \pm 0.1$ & $3.2 \pm 0.1$ & $3.5 \pm 0.1$ & $3.5 \pm 0.2$ & .17 & .71 & .71 \\
\hline Insulin infusion rate $\left(\mathrm{U} \cdot 24 \mathrm{hrs}^{-1}\right)$ & $49 \pm 18^{a}$ & $20 \pm 8$ & $19 \pm 9$ & $43 \pm 20^{a}$ & .82 & .006 & .72 \\
\hline AUC glucose & $137 \pm 15^{a}$ & $190 \pm 12$ & $225 \pm 10$ & $147 \pm 7^{a}$ & .12 & .001 & .28 \\
\hline
\end{tabular}
trations did not change on days 1 and 2 after surgery either in euglycemia or hyperglycemia (control period). There were not significant time or intervention effects or time $\times$ intervention interaction

Table 1. Clinical data during the experimental period

SAP, systolic arterial pressure; DAP, diastolic arterial pressure; AUC, area under the curve of blood glucose concentrations. Units for AUC are blood glucose concentrations $\left(\mathrm{mmol} \cdot \mathrm{L}^{-1}\right) \times 24 \mathrm{hrs}$. Data are expressed as mean \pm sEM. Data were analyzed with repeated measures analysis of variance with intervention (euglycemia/control) and time (day one/day two after surgery) as the two factors. Post hoc analysis was performed, when appropriate, by $t$-test with Bonferroni's adjustment. ${ }^{a} p<.05$ euglycemia vs. control. 
Table 2. Plasma hormone and selected substrate concentrations

\begin{tabular}{|c|c|c|c|}
\hline & Control & Euglycemia & Changes \\
\hline \multicolumn{4}{|l|}{ Insulin $(\mu \mathrm{U} / \mathrm{mL})$} \\
\hline Artery & $38 \pm 8$ & $54 \pm 24$ & $16 \pm 18$ \\
\hline \multicolumn{4}{|l|}{ C-peptide (ng/mL) } \\
\hline Artery & $2.3 \pm 0.7$ & $0.9 \pm 0.3^{a}$ & $-1.4 \pm 0.8$ \\
\hline \multicolumn{4}{|l|}{ Glucose $(\mathrm{mmol} / \mathrm{L})$} \\
\hline Artery & $9.6 \pm 0.6$ & $5.8 \pm 0.4^{b}$ & $-3.8 \pm 0.6$ \\
\hline Femoral vein & $8.6 \pm 0.7$ & $4.9 \pm 0.5^{b}$ & $-3.7 \pm 0.6$ \\
\hline \multicolumn{4}{|c|}{ Phenylalanine $(\mu \mathrm{mol} / \mathrm{L})$} \\
\hline Artery & $107 \pm 5$ & $104 \pm 3$ & $-3 \pm 4$ \\
\hline Femoral vein & $111 \pm 6$ & $107 \pm 3$ & $-4 \pm 4$ \\
\hline \multicolumn{4}{|l|}{ Leucine ( $\mu \mathrm{mol} / \mathrm{L})$} \\
\hline Artery & $112 \pm 8$ & $129 \pm 8^{b}$ & $17 \pm 8$ \\
\hline Femoral vein & $113 \pm 8$ & $128 \pm 9$ & $15 \pm 10$ \\
\hline \multicolumn{4}{|c|}{ Glutamine $(\mu \mathrm{mol} / \mathrm{L})$} \\
\hline Artery & $348 \pm 21$ & $381 \pm 27^{b}$ & $33 \pm 12$ \\
\hline Femoral vein & $380 \pm 23$ & $447 \pm 41$ & $67 \pm 31$ \\
\hline \multicolumn{4}{|l|}{ Arginine $(\mu \mathrm{mol} / \mathrm{L})$} \\
\hline Artery & $157 \pm 16$ & $193 \pm 18^{b}$ & $36 \pm 13$ \\
\hline Femoral vein & $178 \pm 17$ & $199 \pm 17^{b}$ & $21 \pm 8$ \\
\hline \multicolumn{4}{|l|}{ ADMA $(\mu \mathrm{mol} / \mathrm{L})$} \\
\hline Artery & $0.42 \pm 0.07$ & $0.42 \pm 0.04$ & $0.00 \pm 0.06$ \\
\hline Femoral vein & $0.51 \pm 0.04$ & $0.54 \pm 0.04$ & $0.03 \pm 0.06$ \\
\hline \multicolumn{4}{|l|}{ SDMA $(\mu \mathrm{mol} / \mathrm{L})$} \\
\hline Artery & $0.55 \pm 0.03$ & $0.56 \pm 0.05$ & $0.01 \pm 0.04$ \\
\hline Femoral vein & $0.70 \pm 0.04$ & $0.68 \pm 0.05$ & $-0.02 \pm 0.07$ \\
\hline
\end{tabular}

Data are means \pm SEM of pooled values from protocols 1 and 2 obtained at the end of the control and euglycemic periods. ${ }^{a} p=.08 ;{ }^{b} p<.05$, euglycemia vs. control (Wilcoxon matched-pairs signedranks test). ADMA, asymmetrical dimethylarginines; SDMA, symmetrical dimethylarginines.

Table 3. Net balance of glucose and selected amino acids across leg muscle

\begin{tabular}{lccc}
\hline & Control & Euglycemia & Changes \\
\hline Glucose $\left(\mu \mathrm{mol} \cdot 100 \mathrm{cc}^{-1} \cdot \mathrm{min}^{-1}\right)$ & $1.34 \pm 0.60^{a}$ & $2.03 \pm 1.00^{a}$ & $0.69 \pm 0.50$ \\
Phenylalanine $\left(\mathrm{nmol} \cdot 100 \mathrm{cc}^{-1} \cdot \mathrm{min}^{-1}\right)$ & $-11 \pm 3^{a}$ & $-3 \pm 3^{b}$ & $8 \pm 2$ \\
Leucine $\left(\mathrm{nmol} \cdot 100 \mathrm{cc}^{-1} \cdot \mathrm{min}^{-1}\right)$ & $-3 \pm 3$ & $4 \pm 5$ & $7 \pm 4$ \\
Glutamine $\left(\mathrm{nmol} \cdot 100 \mathrm{cc}^{-1} \cdot \mathrm{min}^{-1}\right)$ & $-51 \pm 13^{a}$ & $-97 \pm 22^{a, b}$ & $-46 \pm 22$ \\
Arginine $\left(\mathrm{nmol} \cdot 100 \mathrm{cc}^{-1} \cdot \mathrm{min}^{-1}\right)$ & $-30 \pm 11^{a}$ & $-24 \pm 17$ & $6 \pm 8$ \\
ADMA $\left(\mathrm{nmol} \cdot 100 \mathrm{cc}^{-1} \cdot \mathrm{min}^{-1}\right)$ & $-0.21 \pm 0.14$ & $-0.30 \pm 0.12^{a}$ & $-0.09 \pm 0.15$ \\
SDMA $\left(\mathrm{nmol} \cdot 100 \mathrm{cc}^{-1} \cdot \mathrm{min}^{-1}\right)$ & $-0.22 \pm 0.06^{a}$ & $-0.30 \pm 0.11^{a}$ & $-0.08 \pm 0.10$ \\
\hline
\end{tabular}

Data are means \pm SEM of pooled values from protocols 1 and 2 obtained at the end of the control and euglycemic periods. Negative numbers express net release. ${ }^{a} p<.05$ vs. zero, i.e., significant net release or uptake (Wilcoxon matched-pairs signed-ranks test); ${ }^{b} p<.05$ euglycemia vs. control (Wilcoxon matched-pairs signed-ranks test).

for these hemodynamic or biochemical variables. All patients required exogenous insulin during the control and the euglycemic periods. Insulin administration was significantly lower during the control period than during euglycemia in both groups of patients studied according to protocols 1 and 2. There were not significant time effects or time $\times$ intervention interaction for insulin administration. Area under the curve of glucose concentrations was significantly lower during euglycemia than during the control period in both groups of patients studied according to protocols 1 and 2 . There were not significant time effects or time $\times$ intervention interaction for the area under the curve of glucose concentrations. Plasma glucose, insulin, and C-peptide concentrations, obtained at the end of the euglycemic and control periods in subjects assigned to protocols 1 and 2 , were analyzed with repeated-measures analysis of variance with intervention (euglycemia/control) and time (day 1/day 2 after surgery) as the two factors. There were not significant time effects or significant intervention $\times$ time interaction. Values of plasma glucose were near-normal during the euglycemic period $(5.8 \pm 0.4 \mathrm{mmol} / \mathrm{L})$ and were $70 \% \pm 15 \%$ greater at the end of the hyperglycemic control period. Plasma insulin concentrations were not significantly different at the end of the control or euglycemic periods, possibly because a greater insulin infusion during the inten- sive treatment period was matched by a greater endogenous insulin secretion secondary to hyperglycemia during conventional treatment. In fact, plasma C-peptide concentrations tended $(p=$ $.07)$ to be lower during euglycemia than in the control period. The QUICKI index of insulin sensitivity (25) was improved $(p=.02)$ during the euglycemic period $(0.29 \pm 0.01)$ in respect to the control period $(0.27 \pm 0.01)$. Table 3 shows net balance of glucose across leg muscle calculated during the last 20 mins of the euglycemic and control periods. The rate of glucose uptake across leg muscle tended to be higher during euglycemia, without achieving statistical significance. Nonetheless, fractional glucose uptake across leg muscle (i.e., the ratio between the rates of glucose uptake and delivery to leg muscle) was significantly higher $(p<.05)$ during euglycemia $(16 \% \pm 4 \%)$ than during the conventional treatment $(9 \% \pm 3 \%)$.

Whole Body and Leg Muscle Protein Kinetics. Plasma amino acid concentrations and $\mathrm{L}\left[\right.$ ring $\left.^{-}{ }^{2} \mathrm{H}_{5}\right]$ phenylalanine tracer/tracee ratios in radial artery and femoral vein obtained at the end of the euglycemic and control periods in subjects assigned to protocols 1 and 2 were analyzed with repeated-measures analysis of variance with intervention (euglycemia/control) and time (day 1/day 2 after surgery) as the two factors. There were not significant time effects or significant intervention $\times$ time interaction. Figure 4 shows pooled results of phenylalanine tracer/tracee ratios and concentrations in radial artery and femoral vein obtained during the last 20 mins of the euglycemic and control periods in protocols 1 and 2 . Results show that the subjects were in steady-state conditions at the end of the euglycemic and control periods. Arterial L[ring $-{ }^{2} \mathrm{H}_{5}$ ]phenylalanine tracer/tracee ratio (mean \pm SEM) was significantly $(p<$ $.01)$ higher during euglycemia $(0.0188 \pm$ 0.0013 ) than during the control period $(0.0165 \pm 0.0009)$. Consequently, whole body phenylalanine rate of appearance from whole body proteolysis was significantly lower during euglycemia than during the control period (mean change from control period, $-0.14 \pm 0.03$ $\mu \mathrm{mol} \cdot \mathrm{kg}^{-1} \cdot \mathrm{min}^{-1}$ ) (Fig. 1). Femoral venous $\mathrm{L}\left[\right.$ ring $-{ }^{2} \mathrm{H}_{5}$ ]phenylalanine tracer/ tracee ratios during the euglycemic and control periods were $0.0152 \pm 0.0011$ and $0.0141 \pm 0.0008$, respectively. Arterial phenylalanine concentrations were not significantly different during the eu- 

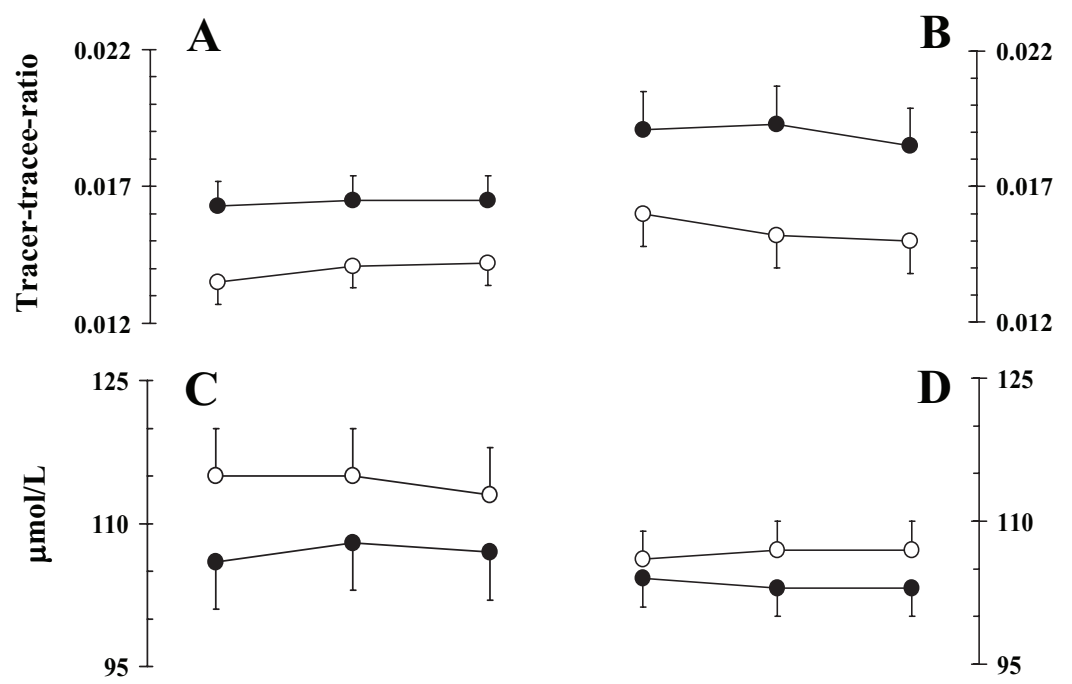

160 ,

170 '

$180^{\prime}$

CONTROL

$160,170^{\prime} \quad 180^{\prime}$

\section{EUGLYCEMIA}

Figure 1. L[ring- ${ }^{2} \mathrm{H}_{5}$ ]phenylalanine tracer/tracee ratios $(A$ and $B)$ and concentrations $(C$ and $D)$ in radial artery (closed circles) and femoral vein (open circles) obtained at the end of the control ( $A$ and $C)$ and euglycemic $(B$ and $D$ ) periods (mean \pm SEM of pooled values from protocols 1 and 2 ).

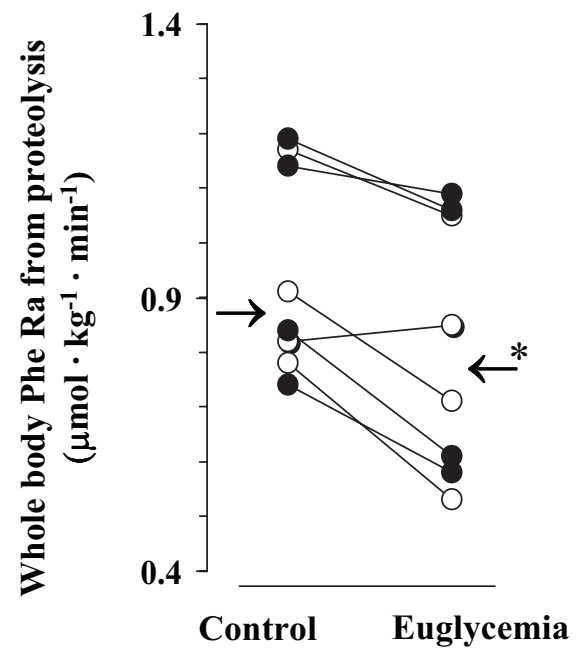

Figure 2. Effects of glucose control on whole body phenylalanine (Phe) rate of appearance $(R a)$ from proteolysis. Individual values of protocol 1 (open circles) and protocol 2 (filled circles). Arrows indicate median values of pooled data. $* p<.05$, euglycemia vs. control (Wilcoxon's matched-pairs signed-ranks test).

glycemic and control periods (Table 2). During the control period, net balance of phenylalanine was significantly lower than zero, indicating a negative balance of muscle protein (Table 3). During euglycemia, values of phenylalanine balance significantly changed from a value that indicated net release to a value that was not significantly different from zero $\left(-3 \pm 3 \mathrm{nmol} \cdot 100 \mathrm{~mL}^{-1} \cdot \mathrm{min}^{-1}\right)$.
Figure 2 shows the rates of leg muscle protein synthesis and degradation during the control and euglycemic periods. Muscle protein synthesis was significantly stimulated by euglycemia (mean change from control period, $21 \pm 6$ nmol phenylalanine $100 \mathrm{~mL}^{-1} \cdot \mathrm{min}^{-1}$ ), whereas rate of protein degradation was not significantly different during the two experimental periods (mean change from control period, $13 \pm 7 \mathrm{nmol}$ phenylalanine $\cdot 100 \mathrm{~mL}^{-1} \cdot \mathrm{min}^{-1}$ ).

Leg Muscle Amino Acid Metabolism. Euglycemia as compared with hyperglycemia was associated with higher arterial leucine $(18 \% \pm 7 \%)$, glutamine $(9 \% \pm$ $3 \%)$, and arginine $(26 \% \pm 14 \%)$ concentrations (Table 2). Glucose control did not change ADMA or SDMA arterial concentrations. Glutamine net balance was significantly lower than zero during both the control and euglycemic periods, indicating constant release of this amino acid from skeletal muscle (Table 3). Net glutamine release was significantly greater during euglycemia than in the control period (Table 3). Leucine net balance across leg skeletal muscle was not different from zero during the two experimental periods (Table 3). Figure 3 shows the effect of glucose control on calculated values of glutamine de novo synthesis and of nonprotein leucine disposal across leg muscle, an index of muscle leucine oxidation. Euglycemia led to a significantly greater glutamine de novo synthe- sis rate in skeletal muscle (mean change from control period, $54 \pm 23 \mathrm{nmol} \cdot 100$ $\mathrm{mL}^{-1} \cdot \mathrm{min}^{-1}$ ). Muscle nonprotein leucine disposal was significantly lower during euglycemia (mean change from control period, $-19 \pm 6 \mathrm{nmol} \cdot 100 \mathrm{~mL}^{-1} \cdot \mathrm{min}^{-1}$ ). Values of net balance of arginine, ADMA, and SDMA are shown in Table 3. Glucose control did not affect arginine, ADMA, and SDMA release from skeletal muscle. Nonetheless, arginine release from skeletal muscle was significantly lower than zero only during the hyperglycemic control period. Rates of ADMA and SDMA release from leg skeletal muscle were significantly different from zero (except for ADMA release during the control period). Muscle proteolysis correlated with rates of ADMA release in euglycemia $(n=8$, $r=-.73, p=.03$ ) and with rates of SDMA release in the control period $(\mathrm{n}=$ $8, r=-.70, p=.05)$; an inverse correlation is due to the fact that muscle proteolysis and net release of ADMA and SDMA from leg muscle are, conventionally, positive and negative figures, respectively).

\section{DISCUSSION}

Cancer and surgical stress interact to aggravate insulin resistance, hyperglycemia, muscle protein catabolism, and amino acid depletion (4, 18-20). We compared the effects of insulin-mediated tight glycemic control and of moderate hyperglycemia, resulting from traditional insulin treatment, on kinetics of protein and selected amino acids in skeletal muscle of female cancer patients receiving total parenteral nutrition after major surgery. Patients received 24 hrs of intensive and conventional insulin treatment on the first and second days after surgery in randomized order. We found that euglycemia as compared with hyperglycemia was associated with: a) stimulated muscle protein synthesis leading to neutral net protein balance, b) lower muscle nonprotein leucine disposal (an index of leucine oxidation) leading to higher plasma leucine concentrations, c) higher de novo muscle glutamine synthesis leading to higher plasma glutamine concentrations, d) higher plasma arginine concentrations by extramuscular mechanisms, e) no changes of muscle release or plasma concentrations of the methylated arginines ADMA and SDMA.

Plasma glucose concentrations were near-normal during the euglycemic period (i.e., about $6 \mathrm{mmol} / \mathrm{L}$ ) and moder- 


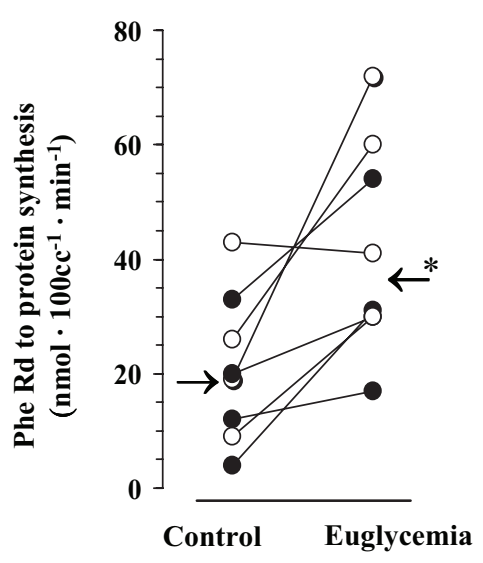

Figure 3. Effects of glucose control on muscle phenylalanine $(P h e)$ rate of disappearance $(R d)$ to protein synthesis and appearance $(R a)$ from proteolysis. Individual values of protocol 1 (open circles) and protocol 2 (filled circles). Arrows indicate median values of pooled data. ${ }^{*} p<.05$, euglycemia vs. control (Wilcoxon's matched-pairs signed-ranks test).
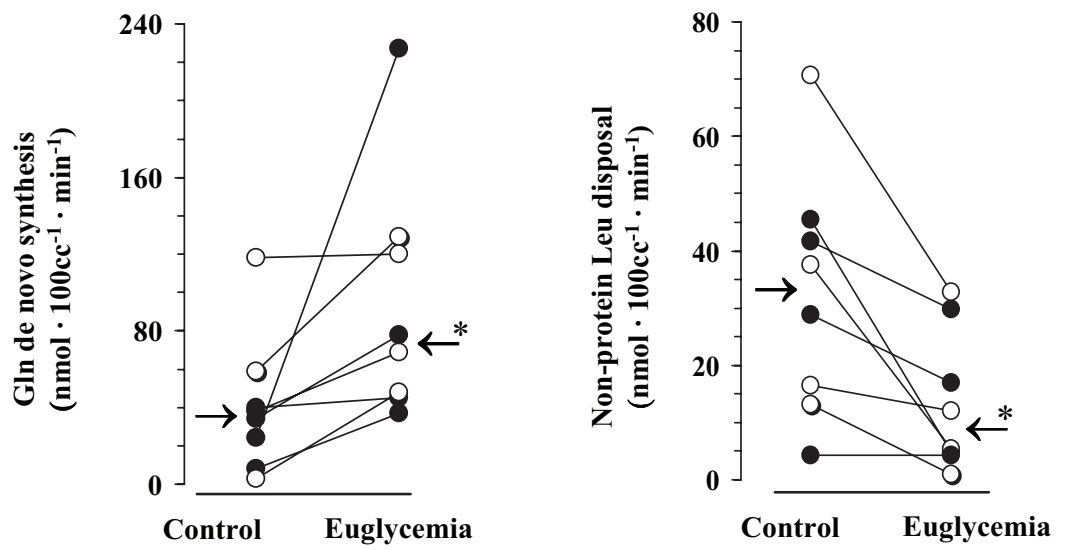

Figure 4. Effects of glucose control on muscle de novo glutamine $(G l n)$ synthesis and nonprotein leucine (Leu) disposal (an index of leucine oxidation). Individual values of protocol 1 (open circles) and protocol 2 (filled circles). Arrows indicate median values of pooled data. ${ }^{*} p<.05$, euglycemia vs. control (Wilcoxon's matched-pairs signed-ranks test).

ately elevated during the control period (i.e., about $10 \mathrm{mmol} / \mathrm{L}$ ). Plasma insulin levels were not significantly different during the two experimental periods. Thus, a greater insulin infusion during the intensive treatment period was possibly matched by a greater endogenous insulin secretion associated to greater plasma Cpeptide caused by hyperglycemia during the conventional treatment period. Differences in plasma glucose levels in the two experimental conditions were much greater than those in insulin concentrations. This clearly indicates that $24 \mathrm{hrs}$ of tight plasma glucose control directly improved insulin sensitivity in our patients. When the quantitative insulin sensitivity check index (25) was calculated from plasma insulin and glucose values, we found that insulin action was significantly improved during euglycemia by $8 \% \pm 3 \%$. In addition, fractional muscle glucose uptake (i.e., rate of leg glucose uptake divided by rate of arterial leg glucose delivery) was significantly greater after intensive insulin treatment. These data are in agreement with previous results in patients with diabetes mellitus showing that insulin-mediated euglycemia directly improves insulin sensitivity and rapidly decreases insulin requirement to maintain euglycemia (27).

Patients were clinically stable during the two study days. However, to prevent potential effects of time-related changes of muscle metabolism after surgery, the euglycemic period either preceded (protocol 1) or followed (protocol 2) the hyperglycemic control period. For example, whereas values of leg plasma flow tended to be higher by $40 \% \pm 24 \%$ during day 1 their averages virtually did not change during the euglycemic and control perithan during day 2 after surgery (Table 1), ods (mean change from control period, $0.2 \pm 0.4 \mathrm{~mL} \cdot \mathrm{min}^{-1} \cdot 100 \mathrm{~mL}^{-1}$ ).

A major finding of this research was that, after 24 hrs of insulin-mediated euglycemia, the rate of glutamine release from skeletal muscle was $>100 \%$ greater than during the conventional treatment period. These changes were presumably due to increased de novo net synthesis of glutamine, assuming no changes in intracellular-free glutamine pool. Plasma glutamine levels changed in parallel to muscle glutamine release, suggesting a cause-effect relationship. In skeletal muscle, glucose serves as the precursor for the carbon skeleton of glutamine. After glycolysis, pyruvate dehydrogenase is the key enzyme responsible for the entrance of pyruvate in the tricarboxylic acid cycle and for providing precursor for glutamine synthesis. The importance of this pathway in critically ill patients is demonstrated by the fact that activation of pyruvate dehydrogenase through dichloroacetate infusion increased intramuscular glutamine concentration, presumably by increasing synthesis of the amino acid (28). Pyruvate dehydrogenase is down-regulated in conditions of insulin deficiency or resistance (29). Increased muscle availability of glucose during physiologic hyperinsulinemia accelerates glucose conversion to glutamine $(12,13)$, whereas such rise in carbon transfer from glucose to glutamine was not observed in insulin-deprived diabetic subjects (11). Taken together, these results suggest that an adequate insulin action is required to promote glutamine synthesis during increased glucose availability, whereas glutamine synthesis is downregulated during absolute or relative insulin deficiency in hypercatabolic patients.

The present study demonstrates that during parenteral feeding after major surgery for cancer, hyperglycemia is associated with muscle protein catabolism, despite an endogenous insulin response. In contrast, euglycemia is associated with neutral protein balance. Our data are in excellent agreement with those of Gore et al. (30), who showed that net muscle protein catabolism is proportional with levels of plasma glucose in severely burned patients. In addition, we suggest that the mechanism of such anabolic effect of euglycemia with improved insulin sensitivity is completely accounted for by protein synthesis stimulation. Conversely, as expected (31), turnover rate of the essential 
amino acid phenylalanine, an index of whole body proteolysis, decreased by $11 \%$ in conditions of normal blood glucose as compared with hyperglycemia. Thus, the anticatabolic action of insulin-mediated euglycemia involves stimulation of protein synthesis in skeletal muscle and inhibition of proteolysis in extramuscular tissues, presumably within the splanchnic region.

Leucine and the other branched-chain amino acids are largely oxidized in skeletal muscle. Their oxidation increases in critically ill patients. Our results show that during euglycemia, the rate of muscle nonprotein leucine disposal (an index of leucine oxidation) was $50 \%$ lower than during the hyperglycemic control period. This observation is consistent with other reports (32) showing that increased plasma glucose with relative insulin deficiency in diabetes is associated with activation of the branched-chain alphaketoacid dehydrogenase, which catalyzes the first step in the leucine oxidation pathway. A greater intracellular leucine availability caused by inhibition of leucine oxidation could have directly stimulated protein synthesis (33) during intensive insulin treatment and euglycemia. In addition, an increased insulin availability could have contributed to stimulate muscle protein synthesis in euglycemia (34).

Arginine depletion has been previously observed in patients with critical illness (35) or cancer (36). In agreement with data obtained in experimental diabetes (37), our results suggest that insulinmediated euglycemia was associated with greater plasma arginine concentration. These changes were mediated by extramuscular mechanisms because rates of leg arginine exchange were not affected by glycemic control. In critically ill patients, high ADMA levels have been associated with increased mortality (10). We have shown (in our knowledge, for the first time) that ADMA and SDMA can be significantly released from leg muscle protein into the bloodstream, thereby contributing to plasma levels of these substrates when proteolysis is accelerated.

\section{CONCLUSIONS}

This study shows that in catabolic patients, skeletal muscle acts as a central effector during hyperglycemia, being at the same time villain and victim to high blood glucose and defective insulin ac- tion. During hyperglycemia with relative insulin deficiency, skeletal muscle greatly decreases its uptake of glucose from systemic circulation, thereby directly increasing blood glucose levels. Conversely, hyperglycemia with relative insulin deficiency promotes muscle wasting and blunted the ability of muscle to provide glutamine to extramuscular tissues. This latter effect could contribute to increased morbidity and mortality in poorly controlled critically ill patients and after surgery. Tight glycemic control optimizes skeletal muscle metabolism, leading to greater systemic availability of glutamine and leucine and to improved insulin sensitivity.

\section{ACKNOWLEDGMENTS}

We thank Mariella Stuma and Anna De Santis for their excellent technical assistance.

\section{REFERENCES}

1. Strommer L, Permert J, Arnelo U, et al: Skeletal muscle insulin resistance after trauma: Insulin signaling and glucose transport. Am J Physiol 1998; 275:E351-E358

2. Langouche L, Vanhorebeek I, Vlasselaers D, et al: Intensive insulin therapy protects the endothelium of critically ill patients. $J$ Clin Invest 2005; 115:2277-2286

3. Biolo G, Fleming RY, Maggi SP, et al: Inverse regulation of protein turnover and amino acid transport in skeletal muscle of hypercatabolic patients. J Clin Endocrinol Metab 2002; 87:3378-3384

4. Biolo G, Zorat F, Antonione R: Muscle glutamine depletion in the intensive care unit. Int J Biochem Cell Biol 2005; 37:2169-2179

5. Jackson NC, Carroll PV, Russell-Jones DL, et al: The metabolic consequences of critical illness: Acute effects on glutamine and protein metabolism. Am J Physiol 1999; 276: E163-E170

6. Gore DC, Jahoor F: Deficiency in peripheral glutamine production in pediatric patients with burns. J Burn Care Rehabil 2000; 21: 171

7. Biolo G, Fleming RY, Maggi SP, et al: Inhibition of muscle glutamine formation in hypercatabolic patients. Clin Sci (Lond) 2000; 99:189-194

8. Beltowski J, Kedra A: Asymmetric dimethylarginine (ADMA) as a target for pharmacotherapy. Pharmacol Rep 2006; 58:159-178

9. van den Berghe G, Wouters P, Weekers F, et al: Intensive insulin therapy in the critically ill patients. $N$ Engl J Med 2000; 345: 1359-1367

10. Nijveldt RJ, Teerlink T, Van Der Hoven B, et al: Asymmetrical dimethylarginine (ADMA) in critically ill patients: High plasma ADMA concentration is an independent risk factor of ICU mortality. Clin Nutr 2003; 22:23-30

11. Hankard RG, Haymond MW, Darmaun D: Role of glucose in the regulation of glutamine metabolism in health and in type 1 insulin-dependent diabetes. Am J Physiol Endocrinol Metab 2000; 279:E608-E613

12. Meyer C, Dostou J, Nadkarni V, et al: Effects of physiological hyperinsulinemia on systemic, renal, and hepatic substrate metabolism. Am J Physiol 1998; 275:F915-F921

13. Meyer C, Woerle HJ, Gerich J: Paradoxical changes of muscle glutamine release during hyperinsulinemia euglycemia and hypoglycemia in humans: Further evidence for the glucose-glutamine cycle. Metabolism 2004; 53:1208-1214

14. Prod'homme M, Rieu I, Balage M, et al: Insulin and amino acids both strongly participate to the regulation of protein metabolism. Curr Opin Clin Nutr Metab Care 2004; 7:71-77

15. Rennie MJ, Bohe J, Smith K, et al: Branchedchain amino acids as fuels and anabolic signals in human muscle. $J$ Nutr 2006; 136(1 Suppl):264S-268S

16. Hesselmann S, Micke O, Bruewer M, et al: Intraoperative radiation therapy (IORT) in primary locally advanced and recurrent carcinoma of the rectum at a "non dedicated" facility. Anticancer Res 2003; 23:412-417

17. Haddock MG, Petersen IA, Webb MJ, et al: IORT for locally advanced gynecological malignancies. Front Radiat Ther Oncol 1997; $31: 256-259$

18. de Blaauw I, Deutz NE, von Meyenfeldt MF: Cancer reduces the metabolic response of muscle to surgical stress in the rat. $J$ Surg Res 1998; 80:94-101

19. Baracos VE: Cancer-associated cachexia and underlying biological mechanisms. Annu Rev Nutr 2006; 26:435-461

20. Ehrmann-Josko A, Sieminska J, Gornicka B, et al: Impaired glucose metabolism in colorectal cancer. Scand J Gastroenterol 2006; 41:1079-1086

21. Biolo G, Iscra F, Bosutti A, et al: Growth hormone decreases muscle glutamine production and stimulates protein synthesis in hypercatabolic patients. Am J Physiol Endocrinol Metab 2000; 279:E323-E332

22. Biolo G, De Cicco M, Dal Mas V, et al: Response of muscle protein and glutamine kinetics to branched-chain-enriched amino acids in intensive care patients after radical cancer surgery. Nutrition 2006; 22:475-482

23. Paroni R, Fermo I, Fiorina P, et al: Determination of asymmetric and symmetric dimethylarginines in plasma of hyperhomocysteinemic subjects. Amino Acids 2005; 28: 389-394

24. Hallemeesch MM, Soeters PB, Deutz NE: Tracer methodology in whole body and organ balance metabolic studies: Plasma sampling is required. A study in post-absorptive rats using isotopically labeled arginine, phenylalanine, valine and leucine. Clin Nutr 2000; 19:157-163 
25. Chen H, Sullivan G, Quon MJ: Assessing the predictive accuracy of QUICKI as a surrogate index for insulin sensitivity using a calibration model. Diabetes 2005; 54: $1914-1925$

26. Wolever TMS, Jenkins DJA: The use of the glycemic index in predicting the blood glucose response to mixed meals. Am J Clin Nutr 1986; 43:167-172

27. Vuorinen-Markkola H, Koivisto VA, YkiJarvinen $\mathrm{H}$, et al: Mechanisms of hyperglycemia-induced insulin resistance in whole body and skeletal muscle of type I diabetic patients. Diabetes 1992; 41:571-580

28. Ferrando AA, Chinkes DL, Wolf S, et al: Acute dichloroacetate administration increases skeletal muscle free glutamine concentrations after burn injury. Ann Surg 1998; 228: 249-256

29. Wu P, Inskeep K, Bowker-Kinley MM, et al:
Mechanism responsible for inactivation of skeletal muscle pyruvate dehydrogenase complex in starvation and diabetes. Diabetes 1999; 48:1593-1599

30. Gore DC, Chinkes DL, Hart DW, et al: Hyperglycemia exacerbates muscle protein catabolism in burn-injured patients. Crit Care Med 2002; 30:2438-2442

31. Flakoll PJ, Hill JO, Abumrad NN: Acute hyperglycemia enhances proteolysis in normal man. Am J Physiol 1993; 265:E715-E721

32. Shimomura Y, Obayashi M, Murakami T, et al: Regulation of branched-chain amino acid catabolism: Nutritional and hormonal regulation of activity and expression of the branched-chain alpha-keto acid dehydrogenase kinase. Curr Opin Clin Nutr Metab Care 2001; 4:419-423

33. Kimball SR, Jefferson LS: Signaling pathways and molecular mechanisms through which branched-chain amino acids mediate translational control of protein synthesis. J Nutr 2006; 136:227S-231S

34. Biolo G, Declan Fleming RY, Wolfe RR: Physiologic hyperinsulinemia stimulates protein synthesis and enhances transport of selected amino acids in human skeletal muscle. J Clin Invest 1995; 95:811-819

35. Luiking YC, Poeze M, Dejong $\mathrm{CH}$, et al: Sepsis: An arginine deficiency state? Crit Care Med 2004; 32:2135-2145

36. Vissers YL, Dejong $\mathrm{CH}$, Luiking $\mathrm{YC}$, et al: Plasma arginine concentrations are reduced in cancer patients: Evidence for arginine deficiency? Am J Clin Nutr 2005; 81:1142-1146

37. Scharff R, Wool IG: Effect of diabetes on the concentration of amino acids in plasma and heart muscle of rats. Biochem $J$ 1966; 99: $173-178$ 